\title{
The E2 trans-activator can act as a repressor by interfering with a cellular transcription factor
}

\author{
Arne Stenlund ${ }^{1}$ and Michael R. Botchan ${ }^{2}$ \\ Department of Molecular Biology, University of California, Berkeley, California 94720 USA
}

The E2 open reading frame (ORF) of the bovine papillomavirus (BPV-1) encodes a family of site-specific DNAbinding proteins. The full-length protein is a transcriptional activator, whereas the polypeptides that contain only the carboxy-terminal domain are repressors. Here we show that the trans-activator can work as a repressor of transcription for one of the BPV-1 promoters by binding to a DNA sequence required for basal activity of the promoter. This operator site is defined as a 12-bp sequence that lies immediately downstream of the cap site. The operator DNA contains sequences that are defined genetically and biochemically as being important for basal level promoter activity. Furthermore, this site has been shown to be protected in a DNase footprint assay using fractionated HeLa cell extracts. The repression does not simply result from E2 blocking RNA polymerase initiation or elongation, because a strong E2-binding site placed at the operator has no repressive effect on transcription when the basal target sequence is placed independently upstream of the promoter. Thus, this is an interesting parallel to a theme well known in prokaryotes, where some site-specific DNA-binding proteins can work as either activators or repressors. In this system, as well as in the prokaryotic systems, the precise position of the binding site relative to other cis signals at the promoter determines the nature of the effects.

[Key Words: E2 trans-activator; transcriptional repression; factor interference]

Received August 24, 1989; revised version accepted October 23, 1989.

Repressors of transcription have been recognized as central to the regulation of gene expression in prokaryotes ever since the seminal contributions by Jacob and Monod (1961). Initially, these proteins were viewed as dedicated repressors, that is, their function was thought to be limited specifically to the turn-off of transcription. This view has changed since it became known that the $\lambda$ repressor could serve as an activator, and the cAMP receptor protein - a known activator - could serve as a repressor of transcription (Taniguchi et al. 1979; Ptashne et al. 1980; Malan and McClure 1984). Although the precise mechanism by which these repressors act is not clear, the proteins are believed to interfere with the formation of an 'open' RNA polymerase-DNA complex at the start site of transcription by directly binding to sites in the DNA, overlapping or proximal to the critical - 10 region of the promoter. For the lac operator, the repressor may not block RNA polymerase from binding to its target but inhibits productive isomerizations that lead to initiation (Straney and Crothers 1987). In other situations, multiple operator sites that act at a distance from the start site are required to repress initiation, but, again, these distal sites are believed to occlude productive RNA polymerase-DNA interactions (Adhya 1989).

1Present address: Cold Spring Harbor Laboratory, Cold Spring Harbor, New York 11724 USA.

${ }^{2}$ Corresponding author.
In the much shorter history of eukaryotic transcriptional control, repressors have only recently emerged as an important component; the initial emphasis has overwhelmingly concerned regulation through positive factors. Thus, the relationships and distinctions between activators and repressors and how they both function is less well defined than in the prokaryotic model systems. The picture that has been emerging in the study of repression of eukaryotic genes by site-specific DNA-binding proteins shows great diversity. In a few notable systems it seems that DNA-binding repressors may work at considerable distances from the proximal cis-acting activator sites required for transcription, and it is conceivable that the repressors act only indirectly in preventing transcriptional initiation in these situations, perhaps through organizing nucleosome phasing or higher order chromatin folding (Johnson and Herskowitz 1985; Hofmann et al. 1989/. In the majority of cases where repression has been detected and the operator site for the effector molecule has been determined, the operator is located very close to, or overlapping, sites known to be important for the activity of the promoter (Zinn et al. 1983; Goodbourn et al. 1986; Lambert et al. 1987; Akerblom et al. 1988; Glass et al. 1988; Han et al. 1989; Koenig et al. 1989). Thus, it has been suggested for several of these cases that the effector molecule represses by interference with activity or binding of crucial transcription factors through binding of the repressor to ad- 
jacent or overlapping sites (Rio and Tjian 1983; Barberis et al. 1987; Akerblom et al. 1988; Lenardo et al. 1989). This seems to be an attractive mechanism, particularly for the cases where the repressor is related to the corresponding activator and shares the same DNA sequence specificity. In the simplest scenario, a repressor could be generated through removal of the activation function in a positive factor to generate a competitor for the positive factor (Lambert et al. 1987). Alternative splicing or modification of a protein could produce such competing forms. This type of mechanism where an activator/repressor pair bind to the same sequence and have antagonistic effects predicts that the repressor in the absence of activator will lack effect. This notion has been tested in several cases and appears to be true (Akerblom et al. 1988; Glass et al. 1988; Koenig et al. 1989). In two specific cases, the mechanism of repression cannot be explained by this straightforward model. First of all, the $\alpha 2$-mediated repression of a-specific genes in yeast requires other regions of the $\alpha 2$ protein that the DNAbinding domain, which is necessary but not sufficient for repression (Hall and Johnson 1987). This is inconsistent with a model that simply requires competition between two different factors for binding to the same site. Also, the proposed model for repression of the cAMP response element by the glucocorticoid receptor would involve factors whose binding sites are adjacent and only partly overlapping and unrelated and does not exclude simultaneous binding of factors (Akerblom et al. 1988; Oro et al. 1988). In these instances, protein-protein interactions may be crucial, as they are in the prokaryotic systems where the distinction between activation and repression is determined by specific steric considerations.

Bovine papillomavirus (BPV-1) has been established as an interesting system for study of gene regulation, as the virus encodes a protein that resembles a mammalian transcription factor, both in structure and in function, from its open reading frame (ORF) E2. A DNA-binding domain located in the carboxy-terminal part of the protein confers sequence-specific binding to DNA, whereas the amino-terminal part of the protein is required for transcriptional activation when the protein is bound to its appropriate binding site (Dostatni et al. 1988; Hawley-Nelson et al. 1988; McBride et al. 1989). Two other viral polypeptides share the carboxy-terminal sequences with E2 and therefore share the same DNAbinding domain. One of these is the internally initiated E2 TR (transcriptional repressor); the other is a spliced product fusing part of the E8 ORF to the carboxy-terminal part of E2 (Lambert et al. 1987; Hubbert et al. 1988; Choe et al. 1989). Both of these shorter E2 products appear to have similar functions in that they can both inhibit the trans-activation function of the full-length $\mathrm{E} 2$ in a competitive fashion.

In this paper we describe an analysis of one of the early promoters in BPV and its regulation by the different forms of E2. We describe a mechanism of repressor action that has been suggested to exist, but has not been clearly demonstrated so far. This mechanism involves what appears to be an interference by E2 protein with transcription through binding to a specific site at the promoter. We deduce that this site is a binding site for a crucial cellular factor by three criteria: (1) Genetically, the intact site, which is completely included in the recognition sequence for $\mathrm{E} 2$, is required for promoter activity in the absence of E2; (2) in vitro transcription activity is reduced by deletion of this site; and (3) previous DNase protection assays revealed that HeLa cell extracts contain proteins that can bind over this element (Stenlund et al. 1987). We show that this operator site neither induces the bound E2 protein to assume a 'negative conformation' (for an example of this form of repression, see Sakai et al. 1988) nor does it function as a road block for initiation or elongation. We also conclude that specificity determinants, other than DNA-binding specificity, must exist that determine whether a given factor will function in a positive or negative manner, because the acting repressor, in this particular case, has been defined previously as a positive transcription factor for other promoter configurations.

\section{Results}

The P1 promoter is repressed by the E2 gene product that binds to the promoter

From our previous studies of one of the promoters in the early region of $\mathrm{BPV}\left(\mathrm{Pl}, \mathrm{P}_{7185}\right)$, we determined that this promoter had reduced activity in $\mathrm{C} 127$ cells transformed by BPV-1 compared to the activity in $\mathrm{C} 127$ cells alone (Stenlund et al. 1987). This implied that some function associated with the virus directly or indirectly could have an inhibitory effect on Pl transcription. Several salient features of the P1 promoter suggested a simple model. First, we had shown that a 28 -bp deletion $3^{\prime}$ to the RNA start site was critical for P1 activity both by in vivo and in vitro transcription assays; second, this internal promoter region was shown to be protected from DNase I cleavage by proteins present in fractionated HeLa cell extracts, reinforcing the notion that critical cellular proteins had to bind to this region (Stenlund et al. 1987); finally, we observed that a putative E2-binding site existed within this region. These results suggested that the E2 trans-activator could, in fact, be the inhibiting factor for the Pl promoter. We decided to test this hypothesis directly. In this experiment a construct carrying the CAT gene driven by the P1 promoter was cotransfected with an $\mathrm{E} 2$ expression vector into HeLa cells. As a control for E2 expression, we used the P2 promoter, which is activated by E2. The structures of the reporter and E2 expression vectors are shown in Figure 1B. Expression of E2, which results in a 20 -fold activation of the P2 promoter, reduces P1 expression $\sim 10$-fold (Fig. 1A). We chose to show only representative examples of our data, but all CAT assays reported were repeated at least three times with internal $\beta$-galactosidase controls. To verify that this repression was the result of the expression of the E2 polypeptide, a mutant E2 was inserted in the expression vector to generate CMVE2 R/K. This 

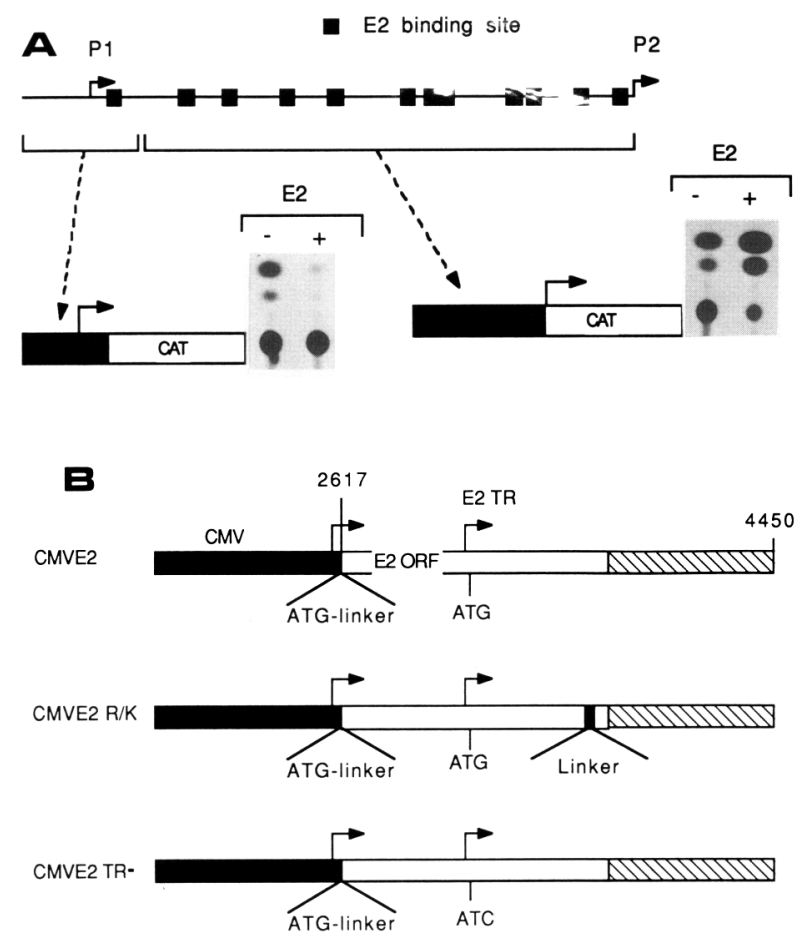

CMVE8/E2

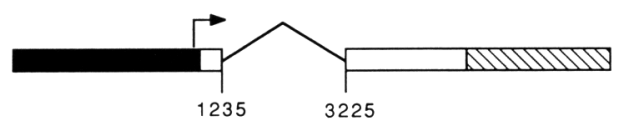

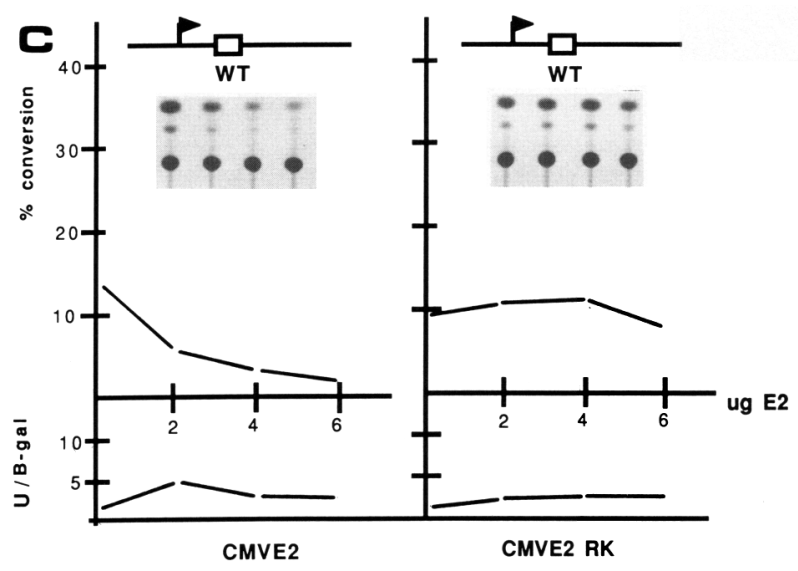

Figure 1. (A) Differential activity of the trans-activator E2 on the P1 and P2 promoters. Fragments containing the P1 and P2 promoters, as shown, were linked to the CAT gene and assayed for their response to E2 by cotransfection with an E2 expression construct (CMVE2). Stimulation of P2 was $\sim 20$-fold, whereas repression of P1 was $\sim 10$-fold. All CAT assays reported in this paper were performed multiple times with internal $\beta$-galactosidase controls. $(B)$ Schematic representation of the different E2 expression constructs used in this study. CMVE2, CMVE2 R/K, and CMVE2 $\mathrm{TR}^{-}$all contain a genomic fragment of BPV DNA containing the E2 ORF linked to the human cytomegalovirus $\beta$ promoter by an ATG linker. CMVE2 R/K has an insertion mutation that destroys the capacity of E2 to bind to DNA. CMVE2 TR- has a point mutation that destroys the initiation codon for the internally promoted repressor form of E2 and can consequently only express the trans-activator form of E2. CMVE8/E2 is a cDNA of a spliced message fusing 11 amino acids from the E8 ORF to the carboxy-terminal part of E2 linked to the cytomegalovirus promoter. This vector makes a form of E2 that binds to DNA but lacks trans-activating domain. $(C)$ Repression of the P1 promoter requires the E2 polypeptide. A P1 CAT construct was assayed for repression through cotransfection with a vector expressing the wild-type E2 (CMVE2, left) or a mutant E2 (CMVE2 R/K, right) that lacks E2-binding capacity. A graph is shown with percent acetylated chloramphenicol plotted for each quantity of E2 expression vector used in cotransfection. (Insets) The autoradiographs from the reactions that were used for quantitation. In each case, a $\beta$-galactosidase-expressing plasmid was used as an internal transfection standard. (Bottom) The $\beta$-galactosidase activity of a fraction of each sample expressed as nmoles of $O$-nitrophenyl- $\beta$-D-galactopyranoside cleaved per minute per milligram of protein.

mutation consists of a linker insertion close to the $3^{\prime}$ end of the E2 ORF and results in a polypeptide that lacks DNA-binding activity (Cripe et al. 1987). Figure 1C shows the results of a side-by-side transfection, comparing the effects of wild-type and mutant E2 on the expression from the $\mathrm{Pl}$ promoter. To control for transfection efficiency, the $\beta$-galactosidase-expressing plasmid pON 260 was included in the transfections and $\beta$-galactosidase activity was measured on a fraction of each sample (Spaete and Mocarski 1985). The results show clearly that the mutation in E2 abolished repression, indicating that the E2 polypeptide is required for the effect and ruling out the possibility that repression is due to promoter competition. The approximately twofold increase in $\beta$-galactosidase activity is reproducibly seen upon cotransfection with the trans-activator E2 and is likely to represent some type of general trans-activation function of E2.

To test whether E2 could bind to the putative binding site immediately downstream of the P1 cap site, a fragment of the E2 ORF was expressed in Escherichia coli; the protein was purified by affinity chromatography using a known E2-binding site and was used for footprint analysis, as shown in Figure 2. The wild-type fragment shows a very clear protection, whereas the +1 mutant, which has a 1-nucleotide insertion in the putative binding site is unable to bind the protein. Furthermore, moving the 12 nucleotides constituting the putative E2binding site to 43 nucleotides upstream of the cap site also moves the footprint, indicating that these $12 \mathrm{nu}$ cleotides are sufficient to direct E2 binding. Elsewhere, we have described a more comprehensive study of this site, which we call E2-binding site 1 (BS1), as well as the other $16 \mathrm{E} 2$-binding sites in the viral genome ( $\mathrm{Li}$ et al. 1989|.

\section{Structure of the P1 promoter}

We have shown that at least part of the P1 promoter sequence is located downstream of the transcriptional initiation site, as transcription in vitro was completely dependent on a sequence that extends 28 nucleotides im- 


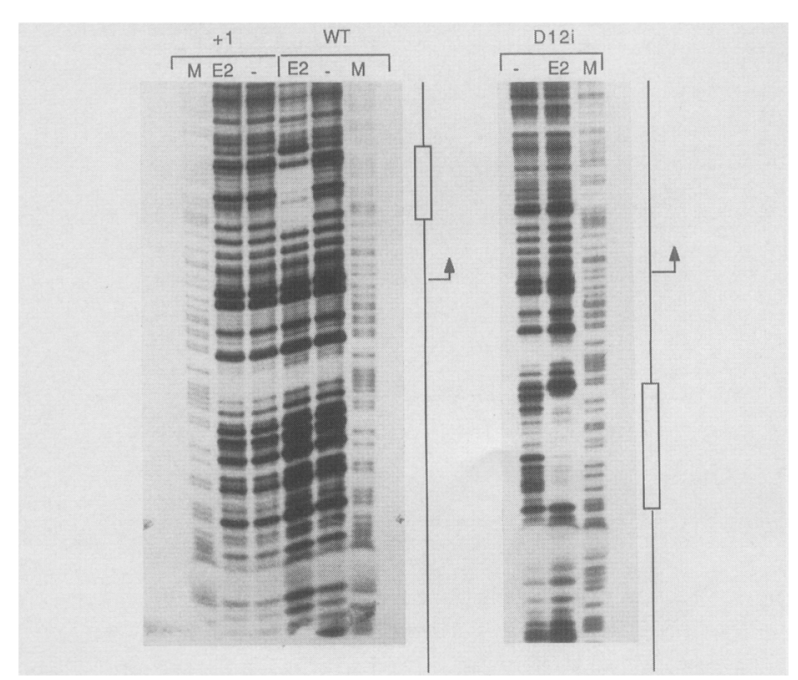

Figure 2. E2 binding to the promoter region of the P1 promoter. DNase footprint assays were performed on three different templates using affinity-purified E2 expressed in E. coli. Binding to the wild-type site has been performed with both full-length and carboxy-terminal E2 proteins (Li et al. 1989). In this particular experiment, the truncated 287 -amino-acid protein was used (see Experimental procedures). The +1 mutant has an insertion of 1 nucleotide between nucleotides 7209 and 7210. The D12i mutant has a deletion between nucleotide 7202 and 7214. These missing 12 nucleotides are, instead, inserted in a position 43 nucleotides upstream of the cap site. Conditions for footprinting were as described by Li et al. (1989).

mediately $3^{\prime}$ to the cap site (Stenlund et al. 1987). The experiments described above show directly that E2 protein can mediate repression of the Pl promoter. To explore the mechanism for this repression further, we wanted to determine where critical genetic elements for the promoter were located and how they were positioned specifically with respect to E2 BS1. Thus, to define the promoter in relation to a putative operator sequence, we investigated the structure of the P1 promoter through generation and assay of deletion mutants. In these assays, promoter activity was measured in the absence of E2. A representative summary of this analysis is shown in Figure 3. The top of Figure 3A shows the constructs and their activity, whereas the bottom shows the sequence of the region, as well as the extent and location of the deletions assayed at top. A fragment shown previously to have promoter activity (HindIII-Nar) was fused to the chloramphenicol acetyltransferase (CAT) gene (HBCAT) in our basic construct. As shown, addition of viral sequences upstream of the HindIII site had no significant effect on CAT activity from the P1 promoter. Deletions from the $5^{\prime}$ end of the HindIII-Nar fragment, up to 42 nucleotides upstream of the cap site, had no deleterious effect on CAT expression, as illustrated by the construct D7143CAT, establishing that the promoter has no requirement for sequences upstream of position -42 .

Deletions from the $3^{\prime}$ end of the HindIII-Nar fragment showed very slight effects up to nucleotide 7255 , whereas further deletion to nucleotide 7214 (i.e., $29 \mathrm{nu}$ - cleotides downstream of the cap site) resulted in reduction of the CAT activity to background levels. We had shown previously that transcription in vitro does not require this distal $3^{\prime}$ region but, instead, is completely dependent on another more proximal sequence downstream of the cap site, between nucleotides 7185 and 7214 (Stenlund et al. 1987). To clarify whether this 7214 deletion affected one contiguous element extending from downstream toward the cap site or possibly two discrete factors, an 8-nucleotide long BamHI linker was inserted at nucleotide 7214 (7214i). This construct retains near wild-type levels of activity, indicating the presence of a separate element downstream of 7214 . This element was further defined through the D20 mutant, which is a deletion between nucleotides 7214 and 7234 accompanied by a linker insertion and lacks activity. The sequence upstream of nucleotide 7214 contains at least two elements absolutely required for expression, as illustrated by mutant D12, which removes the sequences between nucleotides 7201 and 7214 , and mutant D7, which replaces the sequences between nucleotides 7185 and 7194 with a BamHI linker. Both of these deletions show only background levels of activity. That these mutations affect two different elements is demonstrated by the fact that activity can be restored to the D12 deletion construct if the 12 nucleotides that are deleted are inserted at a position 43 nucleotides upstream of the cap site (D12i). Most importantly, this result also shows that these 12 nucleotides contain a functional unit, a notion that is further reinforced by the fact that a precise duplication of this sequence results in an approximately twofold increase in promoter activity, compared to the wild-type construct $(2 \times 12)$. The increased activity of the construct with the duplication is apparent only when the 12 -mers are immediately adjacent, for example, the insertion of 8 nucleotides between the two elements results in a promoter with wild-type level activity (data not shown). These results clearly indicate the presence of at least three elements, A, B, and $\mathrm{C}$, downstream of the cap site (as indicated in Fig. 3A) that are all required for expression. In the following sections, we discuss only one of these elements, the B element.

Interestingly, the 12 nucleotides defined by the D12 deletion coincide completely with the E2 BS1 ACCACACCCGGT. To define the $\mathrm{B}$ element further, the mutants shown in Figure 3B were generated and assayed for CAT activity. The most striking result is that deletion of ACC (mutant 7203/5) or GGT (mutant 7212/14) at either end has no effect on CAT activity, indicating that the central 6 nucleotides may be sufficient for function. The deletions that affect the central 6 nucleotides show the same low-level activity as the D12 deletion. Also, the +1 mutation (which is an insertion of 1 nucleotide) that destroys E2 binding (Fig. 2) still retains wild-type level activity. Note that the insertion of an extra $\mathrm{C}$ does not change the internal sequence but moves the two E2 'half-sites' farther apart. This mutational analysis establishes that the B element activity is completely included in the E2 recognition sequence and is confined to the internal sequence. This point is corroborated by the 


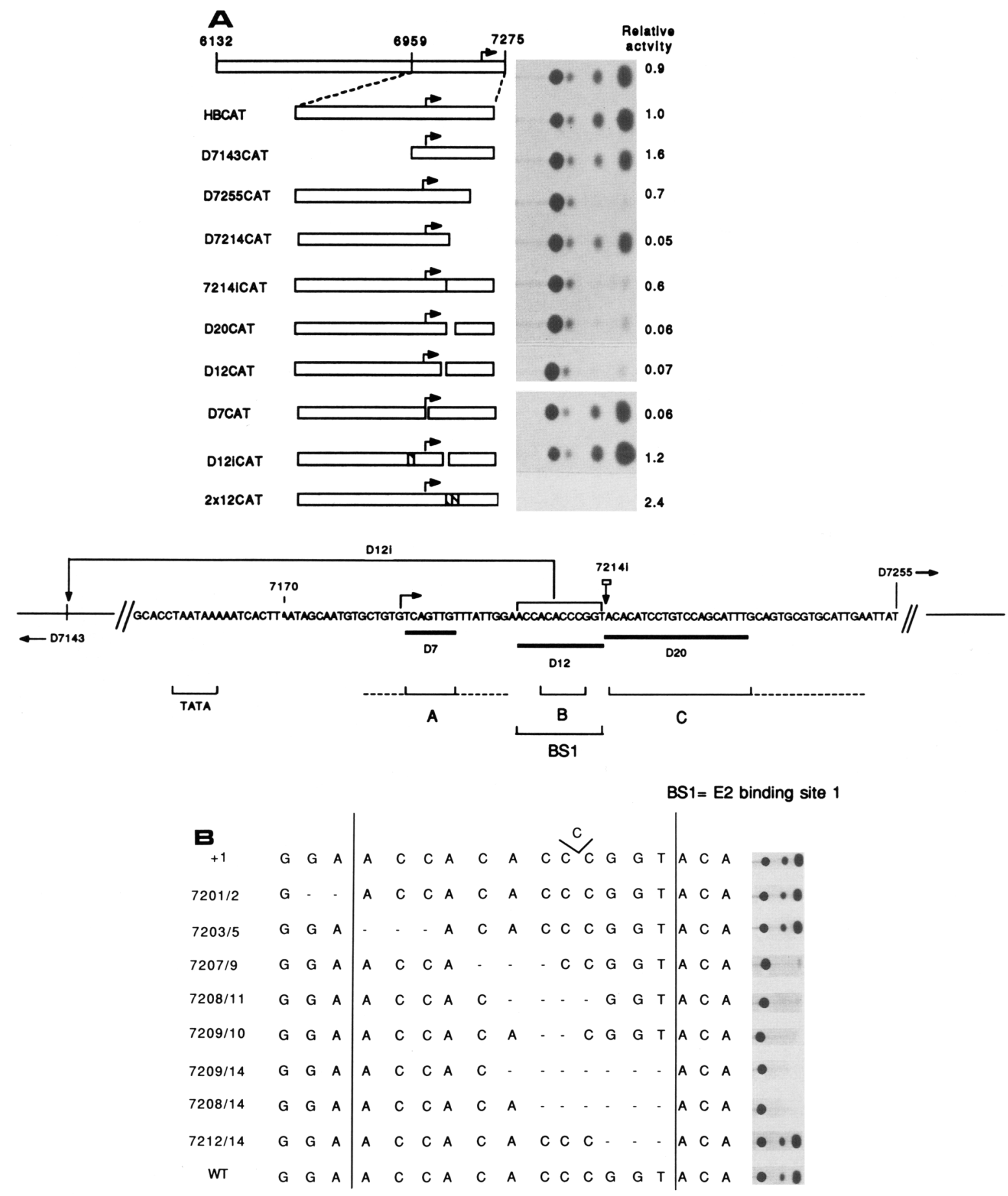

Figure 3. Deletion analysis of the P1 promoter region. Representative autoradiographs of the CAT assays are shown from experiments that have been repeated at least three times with internal $\beta$-galactosidase controls. $(A)$ Summary of the sequence requirements of the P1 promoter in vivo. (Top) $11 \mathrm{P} 1$ constructs and their relative levels of CAT expression are shown; (bottom) the sequence of the promoter region and a diagram of the nature and extent of the mutants at top. The $7214 \mathrm{i}$ mutation is an insertion of an 8-nucleotide BamHI linker between nucleotide 7214 and 7215 . The D12i mutant has the same deletion as D12 but has the missing 12 nucleotides inserted at nucleotide 7143 in the same orientation. The $2 \times 12$ CAT construct has a precise duplication in the wild-type position of these same 12 nucleotides $(7202-7214)$. Below the sequence is a tentative assignment of separate nonoverlapping regions that are required for expression of CAT. These results demonstrated an almost absolute requirement for the B element, which was analyzed further (Fig. 3B). BS1 = E2-binding site 1. (B) Deletion analysis of the B element region. Small deletions and one insertion were generated in the HBCAT background and assayed for CAT activity. Three bases on each side of the element are given to show the resulting recreated sequence in each case. 


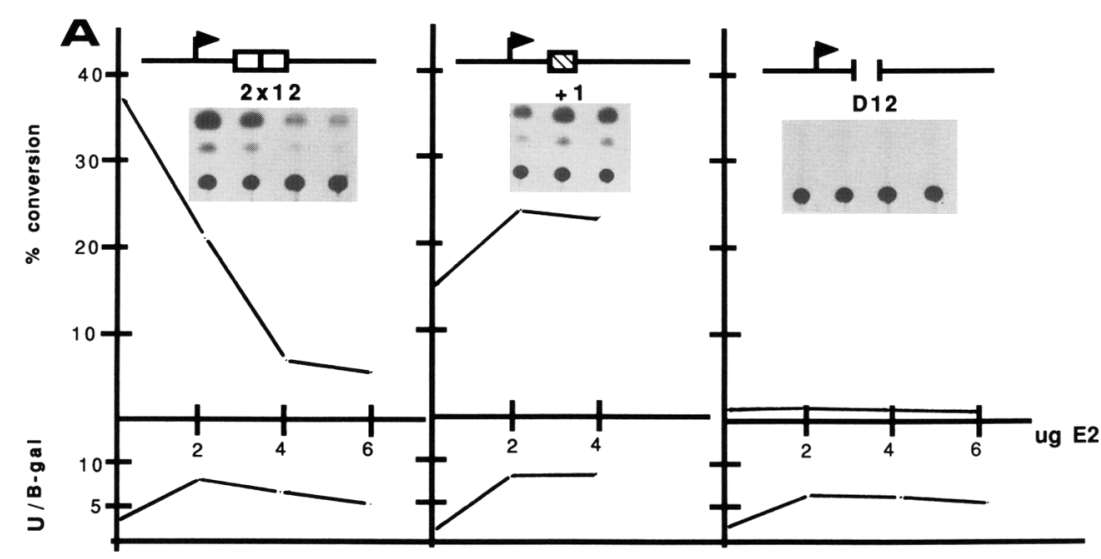

Figure 4. Response of mutant promoters to different forms of E2. (A) Three mutant promoter constructs, $2 \times 12$ with a duplicated E2 binding site, +1 with a 1 -base insertion that destroys E2 binding, and the D12 deletion that deletes the whole E2-binding site, were assayed for their response to cotransfection with increasing amounts of the E2 expression vector CMVE2. $(B)$ The wild-type P1 promoter and the +1 mutant were assayed for their response to the repressor form of E2 through cotransfection with the expression construct CMVE8/E2. The expression construct CMVE2 TR- lacks an initiation codon for the internally promoted repressor form of E2 and can consequently only make the trans-activator form of E2. This construct was cotransfected with the wild-type P1 promoter to demonstrate the ability of the transactivator to act as a repressor.

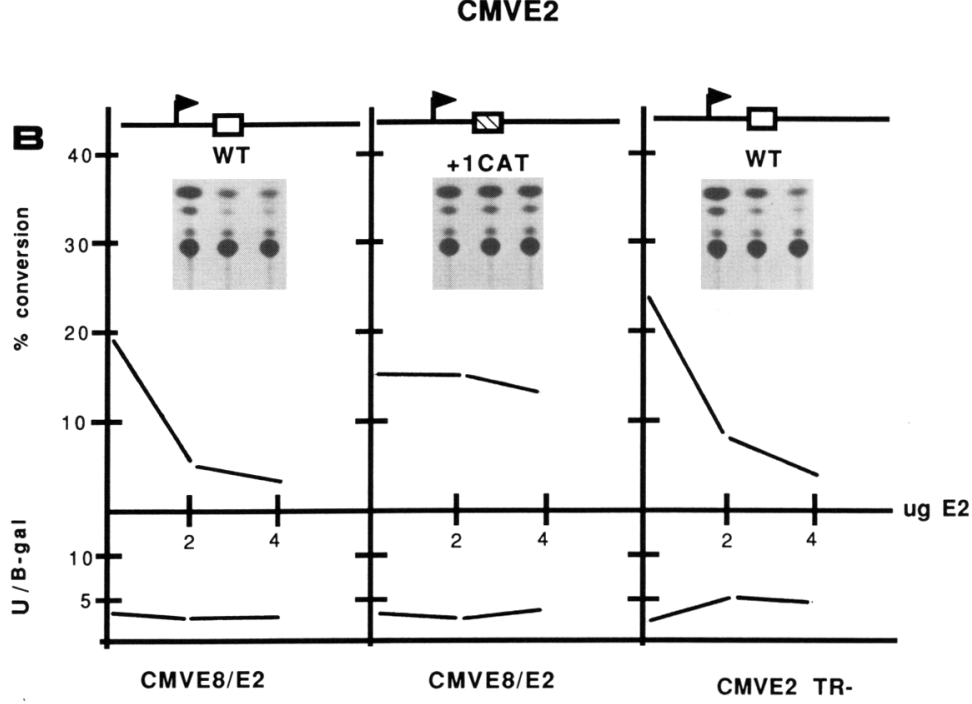

findings that reinsertion of the 12-bp sequence at another position (D12i) restores basal activity and that insertion of an 8-bp linker just $3^{\prime}$ to E2 BS1 has a very slight effect on activity (7214i).

\section{E2 binding is required for repression}

The information gained from the study of the promoter presented us with the opportunity to test several aspects of the nature of repression. First, the fact that the functions of E2 BS1 can be separated, i.e., that E2 binding can be destroyed without affecting the activity of the B element, allowed us to test directly whether binding of E2 to $\mathrm{BS} 1$ is required for repression of the $\mathrm{Pl}$ promoter. As shown in Figure 4A (center), use of a promoter with the +1 mutation in E2 BS1 changes the response to E2 completely compared to use of the wild-type promoter. Instead of being repressed, the promoter is now activated in the presence of E2. The activation is slight and is similar in kinetics and magnitude to the activation that is consistently seen for the $\beta$-galactosidase expression plasmid in the presence of the trans-activator. Clearly, the fact that the Pl promoter is no longer repressed when it carries this particular mutation indicates that binding of E2 is required for repression. This interpretation is also supported by the fact that two other mutants, $7203 / 5$ and $7212 / 14$, which cannot bind E2 (Li et al. 1989) but show wild-type level of activity, also failed to be repressed by E2 (data not shown).

It has been suggested that the E2 trans-activator function is apparent only when the binding motif is present in more than a single copy, and some experiments supporting this notion have been performed (HawleyNelson et al. 1988; Hirochika et al. 1988; Spalholz et al. 1988). Thus, it could be argued that the difference between E2 acting as a repressor for the P1 promoter and an activator for the P2 promoter is based on quantity rather than quality. To test this theory, we assayed the $2 \times 12$ mutant, which contains a duplicated E2-binding site. As shown in Figure 4A (left), this mutant is repressed at least as dramatically as the wild-type construct, with both the initial and repressed levels of activity roughly twofold higher than for the wild-type promoter, arguing against the idea that the number of binding sites is a determinant for repression. The importance of the E2 BS1 region for the P1 promoter is again demonstrated by the D12 deletion, both in the presence and absence of E2 (Fig. 4A, right). 


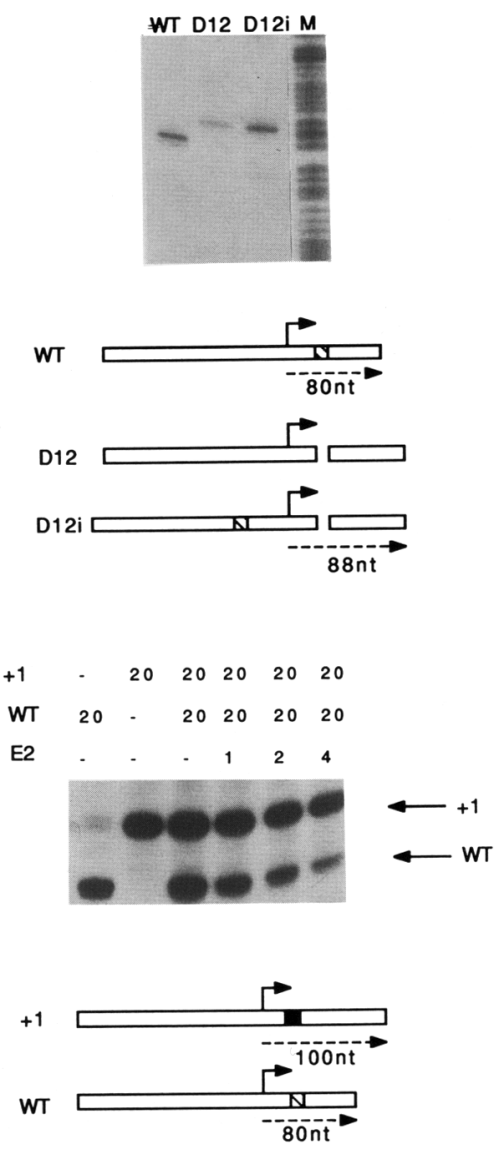

These results argue strongly for a direct involvement of E2 binding in repression of the P1 promoter. We also assayed the activity of the related polypeptide E8/E2, which shares the carboxy-terminal part, including the DNA-binding domain, with E2 and has 11 amino-terminal amino acids from the E8 ORF. As can be seen in Figure 4B, expression of E8/E2 will indeed repress the wild-type P1 promoter, whereas the +1 mutant that lacks the E2 BS1 is unaffected (Fig. 4B, middle). This argues that the amino-terminal part of the E2 protein that is required specifically for trans-activation is dispensable for repression. This result led us to consider the possibility that the repression seen could be the result of activation of the internal E2 TR promoter within the E2 ORF (see Fig. 1B) and expression of the repressor form of E2 in addition to the trans-activator. To address this question, we constructed an E2 expression vector with a point mutation that changes the initiator methionine for E2 TR to an isoleucine (CMVE2 TR $^{-}$; see Fig. 1B). Mutation of this methionine abolishes the ability of this construct to produce the internally coded repressor, as measured both by direct protein analysis and functional tests (P. Lambert and P. Howley, pers. comm.; R. Li and M. Botchan, unpubl.). This mutation has no effect on the trans-activating activity of E2 (data not shown) and, as shown in Figure $4 \mathrm{~B}$ (right), represses the P1 promoter in a manner indistinguishable from the wild-type E2. In multiple experiments, no distinctions could be made be-
Figure 5. (Left) In vitro transcription of the wild-type (WT) D12, and D12i mutants. (WT) Transcription from the D7255 mutant template, which has identical activity in vitro as the wild-type construct. (Bottom) Schematic of the structure of the promoter region and sizes of the protected fragments from the respective templates, indicating that the same cap site is used in the three constructs. (Lane $M$ ) A sequence ladder used as marker. (Right) In vitro repression of the $\mathrm{Pl}$ promoter. The assay for repression used the D7255 mutant with an intact E2binding site as the wild-type construct, where the correctly initiated transcript in an RNase protection assay will give rise to an 80-nucleotide-long protected fragment. The +1 mutant template that lacks a functional E2-binding site will give rise to a 100 -nucleotide-long protected fragment using the same probe. (The mismatch that is created because the template has a 1-nucleotide insertion compared to the probe will not be cleaved under the RNase conditions used.) Twenty nanograms of each template was transcribed individually, and a $1: 1$ mixture of the wild-type and +1 templates was made and aliquoted into four reactions for the repression assay. These four aliquots were then transcribed in the absence or presence of 1,2 , and 4 units of the 287-amino-acid E2 protein described in Experimental procedures. The repression, measured as change in ratio between the wild-type and +1 transcripts was approximately fourfold at the highest concentration of E2.

tween the E2 TR- and other E2 expression vectors with respect to effects on the P1 promoter. This establishes that the activator form of E2 can act as a repressor. Because a large number of reporter constructs were analyzed in the following sections, we refer to Figure 9, which contains schematic representations of experiments, to provide a more convenient overview and summary of our results. The results up to this point are summarized in Figure 9, A, B, and C.

\section{E2 can repress $P 1$ transcription in vitro}

At this point it seemed likely that repression was caused directly by competition for binding between factors. In consequence, we decided that we had sufficient information about the nature of the repression to attempt to reproduce the repression in vitro. This would serve two specific purposes: to show that the effect is directly mediated by the E2 polypeptide and to prove that the repression acts at the level of transcription.

As we have shown previously, the P1 promoter is efficiently transcribed in a HeLa whole-cell extract, initiating transcription at the same cap site as is seen in vivo (Stenlund et al. 1987). Consistent with the in vivo results, as shown in Figure 5 (left), where the transcriptional activity of the wild-type, D12, and D12i are compared, the D12 deletion had reduced transcriptional activity. As is the case in vivo, when the 12-bp sequence 
that is deleted in the D12 deletion was inserted $5^{\prime}$ to the cap site (D12i), the transcriptional activity could be restored. Also, from these experiments it is apparent that the site of transcriptional initiation is unaffected by deleting or moving the B element; the size of the wild-type transcript is reduced because the template that was used (D7255) is 20 nucleotides shorter at the $3^{\prime}$ end. That the position of the cap site is not influenced by the position of the B element rules out the possibility that it is a socalled INR element (Smale and Baltimore 1989). This point is further supported because the P1 promoter appears to contain a functional TATA box, indicated by the fact that deletions that remove the putative TATA motif result in defocusing of initiation sites without substantial reduction in the quantity of transcription /G. Bream and M. Botchan, unpubl.).

The in vitro repression assay was set up in such a way to ensure that even minor changes in expression could be detected. This was accomplished through the use of the +1 mutant template as an internal control, because this template lacks an E2-binding site and is unaffected by E2 repression in vivo. To be able to distinguish between the transcripts arising from the wild-type and the +1 mutant, respectively, the D7255 mutant was used as wild-type template. The transcript from this template gives rise to a protected fragment that is 20 nucleotides shorter than transcripts from the +1 mutant. As shown in Figure 5 (right, lanes 1 and 2), these two templates have very similar activities, as expected. A $1: 1$ mixture of the two templates was made and aliquoted into four transcription reactions to ensure the same ratio of +1 to wild type in all reactions. The indicated number of units of bacterially produced E2 were added and the templates transcribed under otherwise identical conditions. As can be seen in lane 3 , in the absence of E2, the template mixture gives rise to roughly equal amounts of transcription from both templates. Lanes $4-6$ show that the addition of E2 supresses transcription of the wild-type template, indicating that $\mathrm{E} 2$ plays a very direct role in suppression of expression at the level of transcription.

\section{Mechanism of repression}

The downstream position of the E2-binding site and its overlap with element B of the promoter indicate two distinctly different possible mechanisms for E2-dependent repression: (1) E2 bound to the template can interfere with elongation, or (2) E2 can functionally or physically displace a cell factor that binds to the B element, and this cell factor is required for transcription. To test the idea that E2 can sterically interfere with elongation when it is positioned in its normal position downstream of the cap site, we constructed a plasmid where the sequence of the E2-binding site was changed from ACCACACCCGGT to ACCGTTGCCGGT. This mutation destroys the B element and also makes the E2-binding sequence identical to binding site 9 (BS9), which has five times greater affinity for E2 than the original site ( $\mathrm{Li}$ et al. 1989). This construct lacks promoter activity. To activate the promoter to levels comparable to the wild-

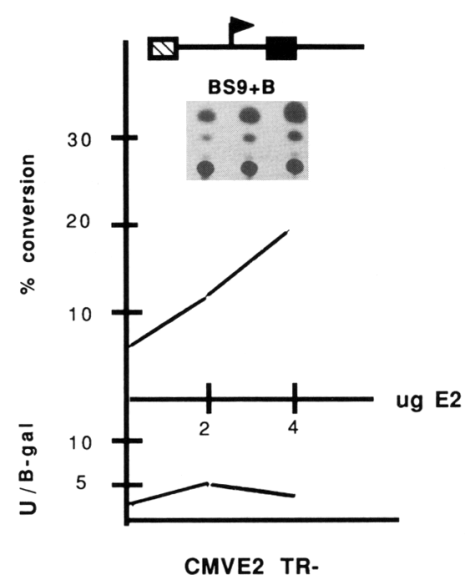

Figure 6. E2 binding downstream of the cap site is not sufficient for repression. The promoter construct BS $9+B$, where BS1 has been replaced by an E2-binding site with a different internal sequence (BS9) in the downstream position and B element activity is provided from the upstream position (nucleotide 7143) was assayed for its response to the trans-activator E2 through cotransfection with CMVE2 $\mathrm{TR}^{-}$. Similar results were obtained with CMVE2 (data not shown). The lack of repression indicates that binding of E2 downstream of the cap site per se is insufficient for repression.

type promoter, a version of E2 BS1 that is crippled for E2 binding but still retains $B$ element activity was introduced in the upstream position at nucleotide 7143. The sequence of this B element was ACCACACCCG. This construct was tested for activity in the absence and presence of E2. As shown in Figure 6, this construct shows no repression; on the contrary, a considerable activation is seen in response to E2, clearly indicating that the mere presence of $E 2$ bound to the template downstream of the cap site is insufficient for repression (for a diagrammatic summary, see Fig. 9D).

On the basis of the increase in activity that is seen in Figure 6, it appears that E2 can act as a positive factor in this position, at least with E2 BS9. This raised some questions about why the trans-activator E2 functions so poorly (or not at all) with E2 BS1 in the downstream position that the net effect is a repression of the promoter. It is possible that E2 BS1 differs in some way from the sites that have been shown to be activators or, alternatively, the specific arrangement of the promoter elements determines what effect E2 will have. To address these questions, we performed the following experiments (Fig. 7): An oligonucleotide containing E2 BS1 was polymerized in seven copies upstream of the SV40 early promoter and assayed in the absence or presence of E2. We determined previously that B elements oligomerized with certain spacings had synergistic effects on promoter activity (see above). To avoid creating an enhancer activity that would stimulate transcription in the absence of E2, a spacing was chosen that lacks this synergistic effect. Cotransfection with the E2-expressing plasmid results in a modest but significant increase in CAT activity (sixfold), indicating that this E2-binding site with E2 provided in trans is capable of activating 


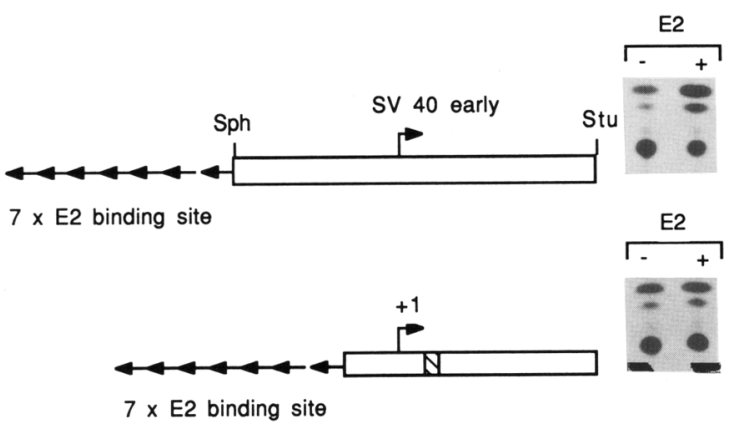

Figure 7. E2 BS1 can activate transcription from the SV40 early promoter. BS1 in the form of an oligonucleotide was polymerized and placed upstream of the SV40 early promoter and the $\mathrm{Pl}$ promoter with the +1 mutation. Cotransfection with CMVE2 $\mathrm{TR}^{-}$resulted in a 6-fold stimulation for the SV40 construct and a 1.4-fold stimulation for the P1 construct. This difference between the response of $\mathrm{Pl}$ and the SV40 promoter to E2 activation is maintained over a wide range of E2 concentrations (data not shown).

transcription and is not dedicated to repression per se. The response of the P1 promoter was tested through construction and assay of a similar construct, where CAT is driven by the P1 promoter carrying the $+1 \mathrm{mu}-$ tation to make the promoter insensitive to $\mathrm{E} 2$ repression from the downstream site. The same seven copies of BS1 were inserted 43 nucleotides upstream of the cap site. This construct does not respond to activation in any significant way (1.4-fold increase), indicating that some feature of the P1 promoter makes it insensitive to activation by $\mathrm{E} 2$ or particularly sensitive to the precise location of the E2-binding sites with respect to other promoter elements. The above experiments apparently eliminate both the roadblock model and the possibility that the sequence of the binding site determines whether E2 will adopt a positive or negative conformation.

We asked whether the overlap between a B element and an E2-binding site always leads to repression by E2, even if the B element is provided separately. Thus, we constructed a promoter that has an additional $B$ element in the upstream position, in addition to a functional B element in the downstream position. The upstream element is wild-type BS1 and can consequently bind E2, whereas the downstream element carries the +1 mutation and therefore cannot bind E2. This construct has the same level of activity as the wild-type promoter and is not repressed by expression of $\mathrm{E} 2$ or $\mathrm{E} 8 / \mathrm{E} 2$, consistent with the interpretation that the overlap between the B element and the E2-binding site is significant only when the particular $B$ element is required for transcription (data not shown; Fig. 9E,F).

A surprising feature of this system is that the positive trans-activating factor E2 has a negative effect on P1 transcription. This result could be the result of the specific context of the E2-binding site with respect to other elements of the promoter. For example, the activating domain of E2 may not be as flexible as that of factor B, thus preventing the necessary contacts from being made, or, perhaps, both proteins form an inactive complex in a position-dependent manner (see Discussion). To test the position dependence of repression, we assayed the D12i construct, where the 12 nucleotides containing BS1 and, consequently, the B element have been moved from their normal position downstream of the cap site to a position 43 nucleotides upstream of the cap (Fig. 9G, H, I). As simply predicted by any model for repression and as shown in Figure 8 (left), this construct can be repressed in a manner indistinguishable from the wildtype promoter upon cotransfection with the E8/E2-expressing plasmid. This result reinforces the idea that repression is due to competition between the B element and E2. Interestingly, as seen in Figure 8 (left), expression of the trans-activator form of E2 does not repress this particular promoter construct. An explanation for this result can perhaps be found in the fact that the two forms of E2 behave differently. Because the known difference between the two species of E2 is the presence of an effector domain in the trans-activator form, but not in $\mathrm{E} 8 / \mathrm{E} 2$, it seems likely that this domain is responsible for the lack of repression. An obvious way that this could function is for the E2 trans-activator in the upstream position to functionally replace the $B$ element and recreate an active promoter that is now dependent on E2 for activity. Clearly, further experiments, including purification of factor $B$, will be needed to understand the position dependence of $\mathrm{E} 2$ repression.

\section{Discussion}

Several possible mechanisms can be envisioned by which transcriptional repression would result from the binding of a factor in the promoter region. Most of these are characterized by steric interference of one kind or another and can be divided into three different groups:

1. Steric interference with binding The binding of the

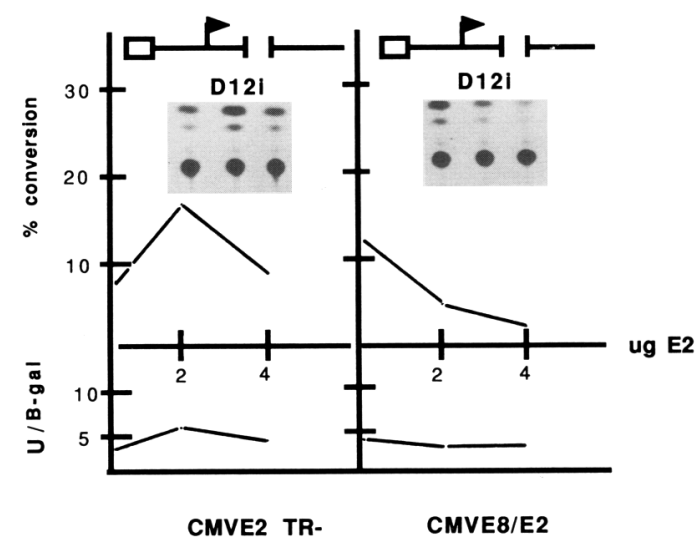

Figure 8. The effect of position on E2-mediated repression. The D12i construct, where the 12 nucleotides constituting the E2-binding site have been moved from their normal position downstream of the cap site to a position 42 nucleotides upstream of the cap site, was assayed for repression through cotransfection with the vector expressing the trans-activator E2 (CMVE2 $\mathrm{TR}^{-}$; left)-similar results were obtained with CMVE2-or the repressor form of E2 (CMVE8/E2; right). 
repressor physically prevents binding of another factor that is required for promoter activity. This type of interference has been suggested in several cases and is certainly the most likely possibility when repression results from competition between proteins that have the same or similar DNA sequence specificity; this includes, for example, E2/E2 TR (Lambert et al. 1987) and the estrogen receptor/thyroid hormone receptor (Glass et al. 1988). In at least the latter case, the repression can be viewed as a lack of activation by the estrogen receptor, because the repressor in the absence of the activator has virtually no effect on the basal level of promoter activity.

2. Steric interference with protein-protein interaction The repressor may prevent a promoter factor from making the appropriate protein-protein contacts by binding to DNA, resulting in masking of a particular activity but without direct competition for DNA binding. Also in this group is a repressor that can interfere with the formation of a transcription complex by forming abortive or otherwise nonfunctional contacts with essential DNA-binding factors, thus preventing the appropriate contacts to be made.

3. Steric interference with elongation Steric interference with elongation is a formal possibility at least when the repressor binds downstream of the transcription initiation site. It has been shown in several cases that the transcription complex seems able to transcribe through regions of template with bound protein, but it is not clear whether this is a general phenomenon or whether accessibility depends on which protein is bound (Bogenhagen et al. 1982; Wolffe et al. 1986). For example, premature termination or abortive initiation may play some role in regulation of expression from the human immunodeficiency virus long terminal repeat (HIV LTR; Toohey and Jones 1989).

From our results on E2-mediated repression of the P1 promoter, we can rule out that repression is the result of interference with elongation for two reasons: When the two overlapping functions, E2-binding and B element activity are spatially separated through replacement of the downstream site with a sequence that lacks B element activity but still retains E2-binding capacity, no repression is apparent, and also at least E8/E2 can act from a considerable distance upstream of the cap site (Fig. 9D,F). Another possibility, that E2 would act as a dedicated repressor and form abortive contacts with other bound factors not overlapping with its binding site, is inconsistent with the fact that both E2 and E8/E2 can act as repressors only when transcription is dependent on the sequence overlapping the E2-binding site (Fig. $9 \mathrm{E}, \mathrm{F})$. This leaves, as the most plausible mechanisms, steric interference either directly with DNA binding of the B factor or with protein-protein interaction between E2 and the factor bound to B at the operator site. We would like to emphasize that our data do not distinguish between these mechanisms and thus refer to repression as due to an interference between factors or a 'functional displacement' of the cell factor by E2. It may
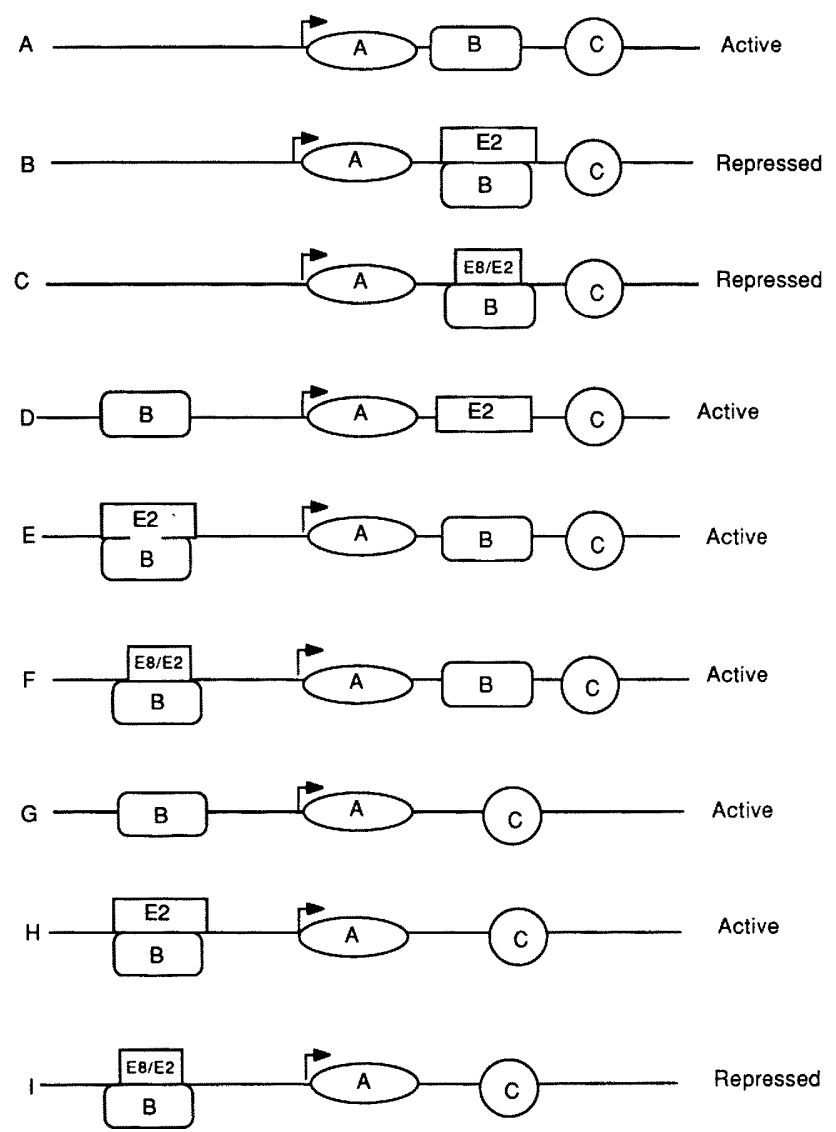

Figure 9. Schematic summary of the promoter configurations used in this paper and the effect on transcription of different forms of E2. $A, B$, and $C$ do not necessarily correspond to single factors but represent the separate regions shown to be required for transcription $(A-C)$ The wild-type configuration; $(D)$ the configuration where an E2-binding site is situated in its normal position but lacks B element activity. B element activity is provided, instead, by a B element that lacks E2-binding activity in the upstream position. $(E$ and $F)$ The configuration where the $B$ element is duplicated, but only the upstream site retains E2binding activity; $(G-I)$ the D12i configuration, where BS1 including the $B$ element, has been moved upstream of the cap site.

seem obvious that the repression is the result of steric interference directly with DNA binding, because the functional B element is completely included within the recognition sequence for E2 binding, and that this arrangement would preclude binding of both factors at once. A closer scrutiny of the sequence arrangements reveals that this might not be the case. On the basis of the detailed examination of the sequences that are required for E2 binding that we and others have performed previously, it appears that the points of recognition by the E2 protein are primarily confined to the major groove (Moskaluk and Bastia 1988; Li et al. 1989) on the flanks of the E2-binding site, specifically the bases ACC and CGGT on both strands. From the deletion analysis, we know that of the 12 nucleotides in the E2-binding site, only the internal sequence ACACCC is required for promoter function. Thus, it seems that even though the 
sites are completely overlapping, very few, if any, nucleotides are shared for recognition by both proteins. Also, if the factor that binds to the internal sequence binds in the major groove, this factor would be located on the opposite side of the helix from where the E2 dimer makes its contacts, and it is consequently possible that both factors can bind simultaneously. In fact, repression may require both proteins to bind simultaneously. In fact, repression may require both proteins to bind simultaneously. Definite resolution of this question and measurement of physical displacement will require purification of the B element activity. Nevertheless, the data clearly show that when E2 binds, overlapping with the cellular factor-binding site in the downstream position, it downregulates P1 transcription.

An interesting observation made here is that the viral factor that displaces the cellular factor physically or functionally, leading to repression of the promoter, can be a positive transcription factor in itself. Although the mechanism of repression can be described in relatively simple terms as competition between a factor that 'works' and a factor that does not, the reason why the trans-activator E2 does not work is more difficult to explain. It has previously been amply demonstrated that E2 can act as an enhancer factor, and from our results, it appears as if E2 also can replace elements of the P1 promoter under certain circumstances. This leads to the conclusion that what ultimately determines the role that the E2 trans-activator will play-repressor, promoter factor, or enhancer factor-is not exclusively dependent on the identity of the factor but is also dependent on the identity of the promoter and the relative position of the binding site for the factor. Presumably, this position dependence is determined by the nature of the trans-activation domains of E2 and the nature of the proteins it generally interacts with to stimulate transcription.

At this point we do not have sufficient information to understand exactly what role the unusual promoter arrangement plays in the ability of P1 to be repressed by the trans-activator E2. From our results, however, it appears that a key element of the repression is the downstream location of the B element/E2-binding site because only in this position, not in the upstream position, is a distinction made between the B element activity and E2. This is of interest because it suggests a difference in polarity or mode of action between $\mathrm{E} 2$ and the B element activity, as the B element works equally well in both positions. What this difference consists of in physical terms is difficult to assess at present, but it seems that not only could specificity of a particular transcription factor be determined through its DNA-binding specificity but through compatibility of effector domains with other proteins interacting at the promoter.

In conclusion, it is interesting to note the versatility of the E2 system as a regulator of gene expression. The combination of the different but related forms of E2, with and without activation domain, and the position or type of binding site leads to a variety of possible regulatory choices. Previously, it was clear that the transcrip- tion units that have been shown to be activated by E2 in a competitive fashion can be repressed by the E2 forms lacking the trans-activating domain (Lambert et al. 1987). This essentially makes an E2-activated promoter sensitive to the activator/repressor ratio. Two further examples of effects of E2 factor binding have now been shown: (1) The wild-type P1 promoter is repressed by both the activator and the repressor forms of E2, that is, it is negatively regulated and sensitive only to the absolute level of specific binding activity, which is the sum of the activator and repressor forms; and (2) in the artificial construct where the E2-binding site is moved upstream of the cap site, the promoter activity is unchanged by the addition of the trans-activator E2, whereas it is repressed by the short form of E2. This spectrum of effects that can be generated mainly through variations in binding site location and context is particularly interesting in light of the many (17) E2binding sites in the early region of BPV-1, most of which are unaccounted for in terms of function. These points are particularly intriguing for the human papillomaviruses, where it has been suggested that the major effects of binding of full-length E2 is to repress transcription from the viral promoters by interference with the formation of an active transcription complex (Thierry and Yaniv 1987; Chin et al. 1989). However, in these cases, it remains to be seen whether this repression is attributable to direct $\mathrm{E} 2$ binding or to other indirect effects of E2 on transcription (Haugen et al. 1988; Heike et al. 1989).

\section{Experimental procedures}

\section{Plasmid DNAs}

Subcloning and plasmid manipulations were carried out as described (Maniatis et al. 1982). Oligonucleotide-directed mutagenesis was performed using a mutagenesis kit supplied by Amersham.

Promoter constructs The basic Pl promoter construct (HBCAT) contains the HindIII-Nar fragment from BPV-1 (nucleotides 6959-7275) fused through a BamHI linker at the Nar site to a fragment from the plasmid CAT 3M (Laimins et al. 1984) that contains the coding sequence for CAT in addition to the small-t antigen splice and the early polyadenylation signals from SV40. This fusion was cloned between HindIII and BamHI in the polylinker of pUC18. All P1 constructs described in Figure $3 \mathrm{~A}$ are derivatives of this construct and are identical, except for the changes that are stated in the text and figures. The deletion mutants shown in Figure 3B have, in addition, a deletion between nucleotides 6959 and 7023 . The construct $\mathrm{D} 12 \mathrm{i}$ is based on the D12 deletion. The 12 nucleotides comprising the deletion were inserted upstream of the cap site in the same orientation in the HincII site at nucleotide 7143 . This insertion was accompanied by a deletion of 4 nucleotides on the upstream side of the HinclI site. The $2 \times 12$ construct is a precise duplication of the 12 nucleotides comprising E2 BS1, in the HBCAT backbone. The BS $9+B$ construct contains two changes compared to the basic HBCAT construct; the BS1 sequence has been converted to BS9 through a change in the sequence from ACCACACCCGGT to ACCGTTGCCGG. In addition, a version of BS1 crippled for E2 binding (ACCACACCCG) was inserted at the HincII site at position 7143 . 
To assay for the transcriptional activation properties of BS1, an oligonucleotide, GATCCTTTATTGGAACCACACCCGGTACA, and its complement were synthesized to generate a double-stranded molecule with cohesive ends. After ligation and digestion with BamHI and BgIII, a directed 7-mer of the oligonucleotide was isolated. This 7-mer was inserted into two different constructs; an SV40-CAT plasmid, which contains a 181-nucleotide Sph-Stu fragment that spans the SV40 early promoter, upstream of a CAT cassette in the polylinker of pUC18. The polymerized oligonucleotide was inserted into the HindIII site immediately upstream of the SV40 fragment. The same 7-mer oligonucleotide was also inserted into the $\mathrm{HB}+1-$ CAT construct at the HincII site at nucleotide 7143 (Fig. 7). The P2 promoter construct in Figure 1 contains a BPV fragment extending between nucleotide 7275 and 93 , including the P2 cap site at nucleotide 89 , linked to a CAT cassette in pUC18.

E2 expression constructs The basic E2 expression vector CMVE2 was constructed by linking a fragment $(\mathrm{Xba}-\mathrm{Sal})$ containing the cytomegalovirus $\beta$-promoter from the plasmid pON 260 (Spaete and Mocarski 1985) to a subgenomic fragment of the BPV early region, extending from SphI at nucleotide 2617 to BamHI at nucleotide 4450 . Through insertion of a synthetic ATG linker between the promoter and the E2 ORF, the aminoterminal sequence is changed from Met-Glu-Thr-Ala to MetAsp-Pro-Gln-Leu-Ala. This change has no apparent effect on the trans-activation or repression properties of the protein. The CMVE2 R/K construct is identical to this construct, except that the E2 ORF contains a linker inserted at nucleotide 3812 , which destroys DNA binding of the polypeptide (Cripe et al. 1987). CMVE2 TR- is identical to CMVE2, except for a point mutation, generated by oligonucleotide-directed mutagenesis, which changes the initiator ATG (Met) for E2 TR to ATC (Ile). CMVE8/E2 has been described previously (Choe et al. 1989).

\section{Transient transfection experiments}

HeLa cells were maintained in Dulbecco's modified Eagle medium (DMEM) with $10 \%$ fetal bovine serum. Transfections were carried out using standard calcium phosphate procedures (Wigler et al. 1978). In all cases, $2 \mu \mathrm{g}$ of reporter plasmid, $1 \mu \mathrm{g}$ of internal standard (pON 260) with varying amounts of E2 expression plasmids, and carrier DNA to a total quantity of $10 \mu \mathrm{g}$ were used. Approximately $12 \mathrm{hr}$ after the addition of precipitate, the cells were treated with $15 \%$ glycerol for $2 \mathrm{~min}$. Cells were harvested for $36 \mathrm{hr}$ after the glycerol shock and divided into two portions, which were assayed for CAT activity and $\beta$-galactosidase, as described. (Gorman et al. 1982; Spaete and Mocarski 1985). Protein concentration in the extracts was determined using Bradford reagents (Bradford 1976).

\section{In vitro transcription assays}

In vitro transcription reactions were carried out using wholecell extracts prepared according to Dynan and Tiian (1983). A standard transcription reaction contained $400 \mathrm{ng} / \mathrm{ml}$ of each supercoiled template, $2 \mu \mathrm{g} / \mathrm{ml}$ of pUC18, $800 \mu \mathrm{g} / \mathrm{ml}$ of unfractionated whole-cell extract, $2 \%$ polyvinyl alcohol, $10 \%$ glycerol, $250 \mu \mathrm{M}$ ATP, UTP, GTP, and CTP, $25 \mathrm{~mm}$ Tris- $\mathrm{HCl} / \mathrm{pH}$ 7.9), $50 \mathrm{~mm} \mathrm{KCl}, 6 \mathrm{~mm} \mathrm{MgCl} 2,0.5 \mathrm{~mm} \mathrm{DTT}$, and $0.5 \mathrm{~mm}$ EDTA. Reactions were carried out at $30^{\circ} \mathrm{C}$ for $30 \mathrm{~min}$. In the repression assays, a derivative of pUC18 that lacks E2-binding sites was used as carrier. The quantity of E2 polypeptide to be used in the transcription reactions was determined using a gel retardation assay with the $\mathrm{P} 1$ promoter fragment as a probe. One unit of activity was defined as the amount of protein required to shift $50 \%$ of 3 fmoles of labeled fragment under tran- scription conditions but in the absence of transcription extract. Under these conditions, four units were capable of shifting $\sim 80 \%$ of the 7 fmoles of template used in the repression assay.

In vitro transcription reactions were extracted with phenol/ chloroform and precipitated with ethanol. Runoff RNA probes were generated through transcription of linearized templates with SP6 polymerase using standard conditions (Melton et al. 1984). The probes were purified on denaturing gels and eluted. Hybridizations were carried out overnight in $80 \%$ formamide, $0.4 \mathrm{M} \mathrm{NaCl}, 1 \mathrm{mM}$ EDTA, and $20 \mathrm{mM}$ PIPES (pH 6.5) at $65^{\circ} \mathrm{C}$. The samples were treated with $40 \mu \mathrm{g} / \mathrm{ml} \mathrm{RNase} A$ and $2 \mu \mathrm{g} / \mathrm{ml}$ RNase $\mathrm{Tl}$ at $15^{\circ} \mathrm{C}$ for $45 \mathrm{~min}$ and analyzed on denaturing gels.

\section{Expression and purification of E2 polypeptide}

For the repression assay, a truncated form of E2 containing the carboxy-terminal 287 amino acids was used. Expression in $E$. coli and purification of the polypeptide was carried out as described (Li et al. 1989), with the following modifications: After sonication of the bacterial lysate in LS buffer [50 mM Tris- $\mathrm{HCl}$ (pH 7.5), $10 \mathrm{~mm}$ EDTA, $0.1 \mathrm{M} \mathrm{NaCl}, 20 \%$ sucrose, $1 \mathrm{~mm} \mathrm{PMSF],}$ the insoluble material was removed by centrifugation at $13,000 \mathrm{~g}$ for $20 \mathrm{~min}$. The protein in the supernatant was precipitated with ammonium sulfate, and the fraction precipitating between $40 \%$ and $60 \%$ was collected. After dialysis against buffer $\mathrm{Z}$ [25 mM HEPES (pH 7.8), $12 \mathrm{~mm} \mathrm{MgCl}_{2}, 1 \mathrm{~mm}$ DTT, $20 \%$ glycerol, $0.1 \% \mathrm{NP}-40$ ] with $0.1 \mathrm{M} \mathrm{KCl}$, this fraction was loaded onto a heparin/agarose column, washed with buffer $\mathrm{Z}$ with $0.2 \mathrm{M} \mathrm{KCl}$, and eluted with buffer $\mathrm{Z}$ with $0.4 \mathrm{M} \mathrm{KCl}$. The peak fractions, as judged by gel retardation assays, were pooled and used for DNA affinity chromatography, as described previously (Li et al. 1989), except that urea was not included in the buffers. The final purity of the E2 polypeptide was $\sim 50 \%$, as judged by Coomassie Blue staining. [DNase footprint assays and gel retardation assays were carried out as described (Li et al. 19891.]

\section{Acknowledgments}

We thank Rong Li for his help in purifying the E. coli E2 proteins. This work was supported by grant MV-91 from the American Cancer Society and a grant from the National Institutes of Health Cancer Institute.

\section{References}

Adhya, S. 1989. Multipartite genetic control elements: Communication by DNA loops. Annu. Rev. Genet. 23: 207.

Akerblom, I.E., E.P. Slater, M. Beato, J.D. Baxter, and P.L. Mellon. 1988. Negative regulation by glucocorticoids through interference with a cAMP responsive enhancer. Science 241: 350-353.

Barberis, A., G. Superti-Furga, and M. Busslinger. 1987. Mutually exclusive interaction of the CCAAT-binding factor and of a displacement protein with overlapping sequences of a histone gene promoter. Cell 50: 347-359.

Bogenhagen, D.F., W.M. Wormington, and D.D. Brown. 1982. Stable transcription complex of Xenopus 5S RNA genes: A means to maintain the differentiated state. Cell 28: 413421.

Bradford, M.M. 1976. A rapid and sensitive method for the quantitation of microgram quantities of protein utilizing the principle of protein-dye binding. Anal. Biochem. 72: 248254.

Chin, M.T., T.R. Broker, and L.T. Chow. 1989. Identification of a novel constitutive enhancer element and an associated 
binding protein: Implications for human papillomavirus type 11 enhancer regulation. J. Virol. 63: 2967-2976.

Choe, I., P. Vaillancourt, A. Stenlund, and M. Botchan. 1989. Bovine papillomavirus type 1 encodes two forms of a transcriptional repressor: Structural and functional analysis of new viral cDNAs. $/$. Virol. 63: 1743-1755.

Cripe, T.P., T.H. Haugen, J.P. Turk, F. Tabatabai, P.G. Schmid, M. Durst, L. Gissman, A. Roman, and L.P. Turek. 1987. Transcriptional regulation of the human papillomavirus- 16 E6-E7 promoter by a keratinocyte-dependent enhancer, and by viral E2 transactivator and repressor gene products: Implications for cervical carcinogenesis. EMBO $/$. 6: 37453753.

Dostatni, N., F. Thierry, and M. Yaniv. 1988. A dimer of BPV-1 E2 containing a protease resistant core interacts with its DNA target. EMBO /. 7: 3807-3816.

Dynan, W.S. and R. Tjian. 1983. Isolation of transcription factors that discriminate between different promoters recognized by RNA polymerase II. Cell 32: 669-680.

Glass, C.K., J.M. Holloway, O.V. Devary, and M.G. Rosenfeld. 1988. The thyroid hormone receptor binds with opposite transcriptional effects to a common sequence motif in thyroid hormone and estrogen response elements. Cell 54: 313-323.

Goodbourn, S., H. Burstein, and T. Maniatis. 1986. The human $\beta$-interferon gene enhancer is under negative control. Cell 45: $601-610$.

Gorman, C.M., L.M. Moffat, and B.H. Howard. 1982. Recombinant genomes which express chloramphenicol acetyltransferase in mammalian cells. Mol. Cell Biol. 2: 1044-1051.

Hall, M.N. and A.D. Johnson. 1987. Homeo domain of the yeast repressor $\alpha 2$ is a sequence-specific DNA-binding domain but is not sufficient for repression. Science 237: 1007-1011.

Han, K., M.S. Levine, and J.L. Manley. 1989. Synergistic activation and repression of transcription by Drosophila homeobox proteins. Cell 56: 573-583.

Haugen, T.H., L.P. Turek, F.M. Mercurio, T.P. Cripe, B.J. Olson, R.D. Anderson, D. Seidl, M. Karin, and J. Schiller. 1988. Sequence-specific and general transcriptional activation by the bovine papillomavirus-1 E2 trans-activator require an $\mathrm{N}$-terminal amphipathic helix-containing E2 domain. EMBO $\mathrm{J}$. 7: 4245-4253.

Hawley-Nelson, P., E.J. Androphy, D.R. Lowy, and E.J. Schiller. 1988. The specific DNA recognition sequence of the bovine papillomavirus E2 protein is an E2-dependent enhancer. EMBO /. 7: 525-531.

Heike, T., S. Miyatake, M. Yoshida, K. Arai, and N. Arai. 1989. Bovine papilloma virus encoded E2 protein activates lymphokine genes through DNA elements, distinct from the consensus motif, in the long control region of its own genome. EMBO J. 8: 1411-1417.

Hirochika, H., R. Hirochika, T.R. Broker, and L.T. Chow. 1988. Functional mapping of the human papillomavirus type 11 transcriptional enhancer and its interaction with transacting E2 proteins. Genes Dev. 2: 54-67.

Hofmann, J.F.-X., T. Laroche, A.H. Brand, and S.M. Gasser. 1989. RAP-1 factor is necessary for DNA loop formation in vitro at the silent mating type locus HML. Cell 57: 725737.

Hubbert, N.L., J.T. Schiller, D.R. Lowy, and E.J. Androphy. 1988. Bovine papilloma virus-transformed cells contain multiple E2 proteins. Proc. Natl. Acad. Sci. 85: 5864-5868.

Jacob, F. and J. Monod. 1961. Genetic regulatory mechanisms in the synthesis of proteins. I. Mol. Biol. 3: 318-356.

Johnson, A.D. and I. Herskowitz. 1985. A repressor (MAT $\alpha 2$ product) and its operator control expression of a set of cell type specific genes in yeast. Cell 42: $237-247$.
Koenig, R.J., M.A. Lazar, R.A. Hodin, G.A. Brent, P. Reed Larsen, W.W. Chin, and D.D. Moore. 1989. Inhibition of thyroid hormone action by a non-hormone binding c-erbA protein generated by alternative mRNA splicing. Nature 337: 659-661.

Laimins, L.A., P. Gruss, R. Pozzatti, and G. Khoury. 1984. Characterization of enhancer elements in the long terminal repeat of Moloney murine sarcoma virus. J. Virol. 49: 183189.

Lambert, P.F., B.A. Spalholz, and P.M. Howley. 1987. A transcriptional repressor encoded by BPV-1 shares a common carboxy-terminal domain with the $\mathrm{E} 2$ transactivator. Cell 50: $69-78$.

Lenardo, M.J., L. Staudt, P. Robbins, A. Kuang, R.C. Mulligan, and D. Baltimore. 1989. Repression of the $\operatorname{IgH}$ enhancer in teratocarcinoma cells associated with a novel octamer factor. Science 243: 544-546.

Li, R., J. Knight, G. Bream, S. Stenlund, and M. Botchan. 1989. Specific recognition nucleotides and their DNA context determine the affinity of E2 protein for 17 binding sites in the BPV-1 genome. Genes Dev. 3: 510-526.

Malan, T.P. and W. McClure. 1984. Dual promoter control of the Escherichia coli lactose operon. Cell 39: 173-180.

Maniatis, T., E.J. Fritsch, and J. Sambrook. 1982. Molecular cloning: A laboratory manual. Cold Spring Harbor Laboratory, Cold Spring Harbor, New York.

McBride, A.A., J.C. Byrne, and P.M. Howley. 1989. E2 polypeptides encoded by bovine papillomavirus type 1 form dimers through the common carboxyl-terminal domain: Transactivation is mediated by the conserved amino-terminal domain. Proc. Natl. Acad. Sci. 86: 510-514.

Melton, D.A., P.A. Krieg, M.R. Rebagliati, T. Maniatis, K. Zinn, and M.R. Green. 1984. Efficient in vitro synthesis of biologically active RNA and RNA hybridization probes from plasmids containing a bacteriophage SP6 promoter. Nucleic Acids Res. 12: 7035-7056.

Moskaluk, C. and D. Bastia. 1988. Interaction of the bovine papillomavirus type 1 E2 transcriptional control protein with the viral enhancer: Purification of the DNA-binding domain and analysis of its contact points with DNA. $J$. Virol. 62: 1925-1931.

Oro, A.E., S.M. Hollenberg, and R.M. Evans. 1988. Transcriptional inhibition by a glucocorticoid receptor $\beta$-galactosidase fusion protein. Cell 55: 1109-1114.

Ptashne, M., A. Jeffery, A.D. Johnson, R. Maurer, B.J. Meyer, C.O. Pabo, T.M. Roberts, and R.T. Sauer. 1980. How the $\lambda$ repressor and Cro work. Cell 19: 1-11.

Rio, D.C. and R. Tjian. 1983. SV40 T antigen binding site mutations that affect autoregulation. Cell 32: 1227-1240.

Sakai, D.D., S. Helms, J. Carlstedt-Duke, J.-A. Gustafsson, F.M. Rottman, and K.R. Yamamoto. 1988. Hormone-mediated repression: A negative glucocorticoid response element from the bovine prolactin gene. Genes Dev. 2: 1144-1155.

Smale, S.T. and D. Baltimore. 1989. the 'Initiator' as a transcription control element. Cell 57: 103-113.

Spaete, R.R. and E.S. Mocarski. 1985. Regulation of cytomegalovirus gene expression: $\alpha$ and $\beta$ promoters are trans activated by viral functions in permissive human fibroblasts. $J$. Virol. 56: 135-143.

Spalholz, B.A., J.C. Byrne, and P.H. Howley. 1988. Evidence for cooperativity between E2 binding sites in E2 trans-regulation of bovine papillomavirus type 1. J. Virol. 62: 31433150 .

Stenlund, A., G.L. Bream, and M.R. Botchan. 1987. A promoter with an internal regulatory domain is part of the origin of a replication in BPV-1. Science 236: 1666-1671.

Straney, S.B. and D.M. Crothers. 1987. Lac repressor is a tran- 
sient gene-activating protein. Cell 51: 699-707.

Taniguchi, T., M. O'Neill, and B. de Crombrugghe. 1979. Interaction site of Escherichia coli cyclic AMP receptor protein on DNA of galactose operon promoters. Proc. Natl. Acad. Sci. 76: 5090-5094.

Thierry, F. and M. Yaniv. 1987. The BPV1-E2 trans-acting protein can be either an activator or a repressor of HPV $18 \mathrm{regu}-$ latory region. $E M B O$ J. 6: 3391-3397.

Toohey, M.G. and K.A. Jones. 1989. In vitro formation of short RNA polymerase II transcripts that terminate within the HIV-1 and HIV-2 promoter-proximal downstream regions. Genes Dev. 3: 265-282.

Wigler, M., A. Pellicer, S. Silverstein, and R. Axel. 1978. Biochemical transfer of single copy eukaryotic genes using total cellular DNA as a donor. Cell 14: 725-731.

Wolffe, A.P., E. Jordan, and D.D. Brown. 1986. A bacteriophage RNA polymerase transcribes through a Xenopus 5S RNA gene transcription complex without disrupting it. Cell 44: $381-389$.

Zinn, K., D. DiMaio, and T. Maniatis. 1983. Identification of two distinct regulatory regions adjacent to the human $\beta$-interferon gene. Cell 34: 865-879. 


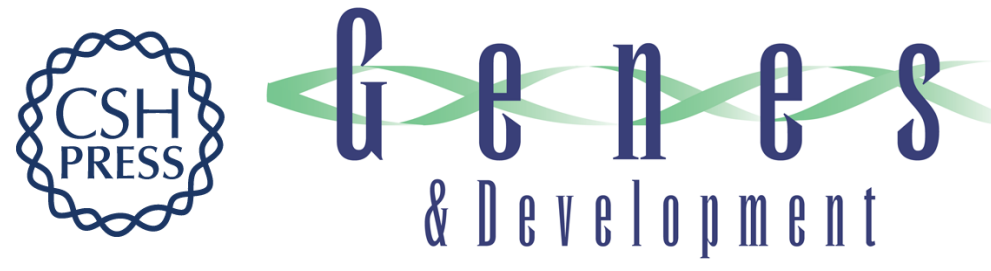

\section{The E2 trans-activator can act as a repressor by interfering with a cellular transcription factor.}

A Stenlund and M R Botchan

Genes Dev. 1990, 4:

Access the most recent version at doi:10.1101/gad.4.1.123

References This article cites 47 articles, 18 of which can be accessed free at:

http://genesdev.cshlp.org/content/4/1/123.full.html\#ref-list-1

License

Email Alerting

Service

Receive free email alerts when new articles cite this article - sign up in the box at the top right corner of the article or click here.

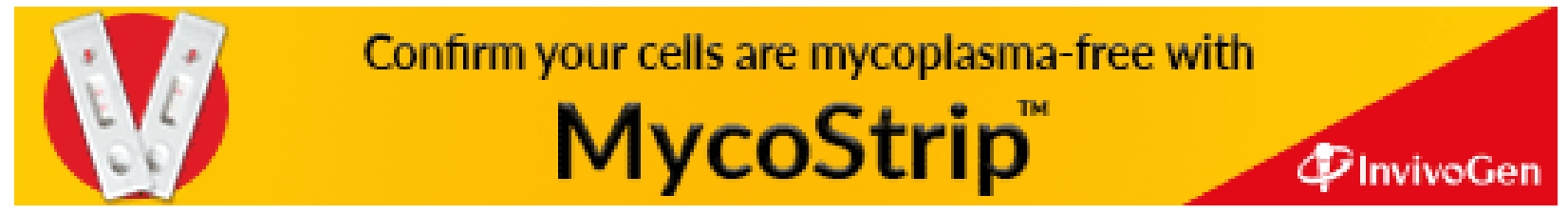

